\title{
A TECNOLOGIA COMO INSTRUMENTO DEMOCRATIZADOR DO DIREITO À EDUCAÇÃO NOS TEMPOS DA PANDEMIA CAUSADA PELA COVID-19
}

\section{Cláudia Mansani Queda de Toledo* Lívia Pelli Palumbo*}

RESUMO: O presente artigo tem por escopo os contornos do direito à educação e o novo modelo educativo do ensino-aprendizagem, extensão e pesquisa, para a modalidade virtual, em razão do isolamento social ocasionado pela pandemia do coronavírus, que inclui a participação dos atores (instituições, docentes e discentes) e o auxílio da tecnologia, da internet e das plataformas digitais, vez que a sala virtual substituiu a convencional. A pesquisa mostra-se relevante: a efetivação da educação formal, autonomia universitária e o emprego da tecnologia nesse período, de modo que as ferramentas digitais se apresentam como o instrumento democratizador à efetivação do direito à educação.

Palavras-chave: Direito à educação; Estado Democrático de Direito; Dignidade humana; Novo coronavírus; Ferramentas digitais.

\section{TECHNOLOGY AS A DEMOCRATIZING INSTRUMENT OF THE RIGHT TO EDUCATION IN THE TIMES OF THE PANDEMIC CAUSED BY COVID-19}

\begin{abstract}
The scope of this article is the contours of the right to education and the new educational model of teaching-learning, extension and research, for the virtual modality, due to the social isolation caused by the coronavirus pandemic, which includes the participation of the actors (institutions, teachers and students) and the aid of technology, the Internet and digital platforms, since the virtual room has replaced the conventional ones. The research is relevant: the realization of formal education, university autonomy and the use of technology in this period, so that digital tools present themselves as the democratizing instrument for the realization of the right to education.
\end{abstract}

Keywords: Right to education; Democratic Rule of Law; Human dignity; New coronavirus; Digital tools.

\section{INTRODUÇÃO}

\footnotetext{
* Doutora em Direito Constitucional (Sistema Constitucional de Garantia de Direitos pela Instituição Toledo de Ensino, Bauru/SP). Mestra em Direito das Relações Sociais pela Pontifícia Universidade Católica de São Paulo. Docente nos cursos de graduação, pós-graduação lato e stricto sensu do Centro Universitário de Bauru. Reitora do Centro Universitário de Bauru. Endereço postal: Praça 9 de Julho, no 51, Vila Pacifico, Bauru - SP, 17050790. E-mail: quedatoledo@uol.com.br.

* Doutoranda em Direito Constitucional (Sistema Constitucional de Garantia de Direitos pela Instituição Toledo de Ensino, Bauru/SP). Mestra em Direito pela Instituição Toledo de Ensino. Especialista em Justiça Constitucional e Tutela de Direitos Humanos pela Universidade de Pisà. Professora do Centro Universitário de Bauru - ITE e da Faculdade Iteana de Botucatu e professora concursada no IMESB (Bebedouro/SP). Endereço postal: Rua Moysés Leme da Silva, $\mathrm{n}^{\mathrm{o}}$ 5-49, Jardim Aeroporto, Bauru/SP, CEP 17017-335. Email: livia.ppalumbo@gmail.com.
} 
A situação atual do Brasil - e de todo o mundo, é de isolamento social e proibição de aglomeração, como medidas para prevenir o avanço do contágio do coronavírus e, como consequência, alterações nas rotinas escolares, vez que a aula não pode ser leciona nos moldes tradicionais. O estudo em tela buscou analisar os caminhos vislumbrados pelas faculdades para não haver prejuízo ao ensino de seus alunos.

A solução vislumbrada pelas academias científicas, em especial, de ensino superior, foi o uso da comunicação remota por meio da tecnologia, em que os professores se valem de aplicativos com sala virtual e ao vivo, com interação - em tempo real - dos alunos, o uso de plataformas virtuais com a socialização de material de estudo, bem como de bibliotecas virtuais.

Apesar de não concorrer com o contato físico, essa solução alcança a necessidade da manutenção das rotinas de estudo e, assim, a garantia da manutenção do direito à educação.

O esforço e comprometimento dos docentes e instituições de ensino superior estão e busca do objetivo de efetivar o direito à educação, em meio a necessidade - de toda a sociedade - de atuação baseadas na união, na fé, na solidariedade, na empatia e nos esforços comuns.

O estudo em tela busca contribuir com a academia, por meio de um diálogo institucional nesse período de crise em razão da pandemia do COVID-19, bem como construir um referencial teórico e metodológico para fundamentar os debates.

A preocupação com o tema se dá pela busca de um diálogo institucional e o alcance da função da academia científica, como efetivação do direto fundamental e social à educação, como elemento transformador do Estado Democrático de Direito e da dignidade humana, sendo que, somente com a concretização desse direito - nesse momento, por meio da tecnologia -, o modelo de Estado será efetivamente democrático, com igualdade de oportunidades, proteção ao mínimo existencial e respeito às divergências.

A pesquisa apresenta um recorte metodológico para tratar do direito à educação, como direito fundamental e social, previsto na Carta Política de outubro de 1988, não adentrando na questão do aspecto do ensino, dividido em educação básica e ensino superior.

A metodologia utilizada neste estudo é a revisão bibliográfica crítica, com base na Constituição Federal e na Lei de Diretrizes e Bases da Educação Nacional, em artigos científicos e doutrina sobre o direito à educação e a tecnologia e, em especial, pela 
contribuição, na prática, do uso da tecnologia como instrumento democratizador do direito à educação nos tempos de pandemia de COVID-19.

\title{
2 O DIREITO FUNDAMENTAL E SOCIAL À EDUCAÇÃO, A AUTONOMIA UNIVERSITÁRIA E O ESTADO DEMOCRÁTICO DE DIREITO
}

Antônio Joaquim Severino (2016, p. 65) explica que a problemática se denota como desvelamento da situação de conflito que provocou o autor para a busca de uma solução, que é tomada em sentido amplo e visa levantar, para a discussão e reflexão, as questões do texto. Nessa toada, a problemática do estudo em tela busca contribuir com as universidades, por meio de um diálogo institucional no período de isolamento social em virtude da pandemia do COVID-19 e construir um referencial teórico e metodológico, com fundamentação na efetivação do direito fundamental e social à educação, como direito de segunda encarnação e o exercício da função da universidade com a utilização da tecnologia e os meios de comunicação remota, de sorte a tecnologia configura - diante desse novo cenário - como elemento transformador do Estado Democrático de Direito e da dignidade humana

\subsection{Direito à educação: conceito e tratamento constitucional}

A educação demonstra-se como um direito de trato contínuo e permanente e, segundo Émile Durkheim (1978, p. 41-42), uma ação que tem por

\begin{abstract}
tem por objetivo suscitar e desenvolver, na criança, certo número de estados físicos, intelectuais e morais, reclamados pela sociedade política, no seu conjunto, e pelo meio especial a que a criança, particularmente, se destine.

[...] a educação consiste numa socialização metódica das novas gerações. Em cada um de nós, pode-se dizer que existem dois seres. Um, constituído de todos os estados mentais que não se relacionam senão conosco mesmos e com os acontecimentos de nossa vida pessoal; é o que poderia chamar de SER INDIVIDUAL. O outro é um sistema de ideias, sentimentos e hábitos, que exprime em nós, não a nossa individualidade, mas o grupo ou os grupos diferentes de que fazemos parte; tais são as crenças religiosas, as crenças ou práticas morais, as tradições nacionais ou profissionais, as opiniões coletivas de toda espécie. Seu conjunto forma o SER SOCIAL. Constituir esse ser social em cada um de nós - tal é o fim da educação.
\end{abstract}

A educação, como processo complexo de transmissão de conhecimentos, valores e experiências (SOUZA, 2010, p. 13) e permite a interação social,

propiciando-lhes meios e instrumentos para que possam manter, aprimorar e, posteriormente, retransmitir a seus sucessores o arcabouço cultural, os valores e os comportamentos adequados à vida em sociedade e indispensáveis para o processo de 
evolução social rumo a um efetivo Estado Democrático de Direito, que deve ter por premissa a consagração da dignidade da pessoa humana (SOUZA, 2010, p. 9).

A educação divide-se em informal e formal, sendo esta última, denominada de ensino que compreende a educação básica e o ensino superior - este como objeto específico do presente estudo.

Nessa toada, a educação engloba o ensino e este possui como principal propósito o desenvolvimento do homem como cidadão, de modo a desempenhar o seu papel na humanidade. Nessa conformidade, "a educação é um processo de reconstrução de experiência, sendo atributo da pessoa humana" (SOUZA, 2012, p. 82), de sorte, o papel da escola é o desenvolvimento da pessoa nas áreas não só do conhecimento, mas também da sociabilidade e da inteligência emocional.

A educação formal desenvolve-se sistematicamente, de acordo com planos formais que incluem conteúdo e meios previamente para atingir objetivos intencionalmente determinados, sendo de regra ministrado em unidades educacionais da rede pública ou privada. Sendo, portanto, o ensino mais específico e programado.

\subsection{O direito fundamental e social à educação: um direito de segunda encarnação}

O direito à educação - direito público e subjetivo - busca a igualação de oportunidades entre as pessoas, bem como o respeito às diversidades e o preparo individual na sua função social em relação à coletividade, como exercício da cidadania, de uma sociedade justa e igualitária e, nessa esteira, e o respeito à dignidade humana e ao modelo democrático de Estado.

Para Paulo Freire (1996), ensinar "é criar possibilidades para a própria construção do conhecimento ou sua produção".

Fernando Savater (2015) expõe que: “A educação quer formar pessoas completas, capazes de utilizar a democracia de uma maneira crítica e positiva. $\mathrm{O}$ cidadão democrata não é uma coisa espontânea, algo que nasce como as flores ou os animais selvagens. Ele é uma obra de arte social."

$\mathrm{O}$ direito à educação possui arcabouço protecionista, em âmbito interno e internacional, nesta, a previsão na Declaração Universal de Direitos Humanos, de 1948, que é a normativa contemporânea primária dos direitos humanos, em seu artigo 26 , in verbis:

Artigo 26 
1. Todo ser humano tem direito à instrução. A instrução será gratuita, pelo menos nos graus elementares e fundamentais. A instrução elementar será obrigatória. A instrução técnico-profissional será acessível a todos, bem como a instrução superior, esta baseada no mérito.

2. A instrução será orientada no sentido do pleno desenvolvimento da personalidade humana e do fortalecimento do respeito pelos direitos do ser humano e pelas liberdades fundamentais. A instrução promoverá a compreensão, a tolerância e a amizade entre todas as nações e grupos raciais ou religiosos e coadjuvará as atividades das Nações Unidas em prol da manutenção da paz.

3. Os pais têm prioridade de direito na escolha do gênero de instrução que será ministrada a seus filhos.

Na sequência, a proteção do direito à educação pelo Pacto Internacional dos Direitos Econômicos, Sociais e Culturais seu protocolo complementar opcional, que também trata do direito à educação, em seus artigos 13 e 14. Ainda, por meio deste documento internacional, é determinado aos Estados aderentes que assegurem e incentivem a educação base, permitindo o acesso universal; em relação ao ensino superior, de acordo com as capacidades de cada um.

Em âmbito interno, a Constituição Federal de 1988 é o primeiro texto constitucional que prevê, de forma específica e detalhada, o direito à educação, com seção específica (artigos 205 a 214), além de disposições ao longo do texto.

\begin{abstract}
A seção específica inicia-se com a declaração de que a educação é um direito de todos, o que caracteriza simultaneamente como um direito individual e difuso, [...], e os objetivos a que deve visar, a saber, o pleno desenvolvimento da pessoa, seu preparo para a cidadania e sua qualificação para o trabalho. Essa norma do art. 205 permite-nos vislumbrar a importância dada à educação (ARAUJO, NUNES JÚNIOR, 2018, p. 637).
\end{abstract}

Dessa forma, o objetivo do legislador foi o de atribuir justiciabilidade ao direito à educação, “caso o Poder Público peque no seu dever de prestar educação, tal direito pode, e deve, ser reivindicado judicialmente (ARAUJO, NUNES JÚNIOR, 2018, p. 637)”.

Por todos, deve-se entender a literalidade da expressão, bem como a universalidade do direito, conforme disposto no artigo 205 da Constituição Federal e artigo $2^{\circ}$ da Lei de Diretrizes e Bases da Educação Nacional (Lei n. 9.394/96), in verbis:

\footnotetext{
Art. 205, CF. A educação, direito de todos e dever do Estado e da família, será promovida e incentivada com a colaboração da sociedade, visando ao pleno desenvolvimento da pessoa, seu preparo para o exercício da cidadania e sua qualificação para o trabalho.

Art. $2^{\circ}$, LDB. A educação, dever da família e do Estado, inspirada nos princípios de liberdade e nos ideais de solidariedade humana, tem por finalidade o pleno desenvolvimento do educando, seu preparo para o exercício da cidadania e sua qualificação para o trabalho.
}

"Não obstante ter iniciado a" matéria com a declaração de um direito tão amplo 
como a educação, na verdade os próximos artigos restringem-se mais ao direito ao ensino e à educação escolarizada formal, pois é esta parte da educação que reclama mais atuação estatal (ARAUJO, NUNES JÚNIOR, 2018, p. 637).

Nessa esteira, o artigo 206 do texto constitucional dispõe acerca da

\begin{abstract}
principiologia do ensino, princípios ricos, pródigos em cientificidade e largos em seus objetivos, que servirão de vetores para toda a atividade legislativa, administrativa e judiciária, não podendo nunca qualquer um dos titulares dessas atividades agir em desacordo com tais princípios (ARAUJO, NUNES JÚNIOR, 2018, p. 637-638).
\end{abstract}

Seguida da Lei de Diretrizes e Bases da Educação Nacional, que prevê os princípios que devem reger o ensino no seu artigo $3^{\circ}$ :

O ensino será ministrado com base nos seguintes princípios:
I - igualdade de condições para o acesso e permanência na escola; II - liberdade de
aprender, ensinar, pesquisar e divulgar a cultura, o pensamento, a arte e o saber; III -
pluralismo de ideias e de concepções pedagógicas; IV - respeito à liberdade e apreço
à tolerância; V - coexistência de instituições públicas e privadas de ensino; VI -
gratuidade do ensino público em estabelecimentos oficiais; VII - valorização do
profissional da educação escolar; VIII - gestão democrática do ensino público, na
forma desta Lei e da legislação dos sistemas de ensino; IX - garantia de padrão de
qualidade; X - valorizaçãa da experiência extraescolar; XI - vinculação entre a
educação escolar, o trabalho e as práticas sociais; XII - consideração com a
diversidade étnico-racial; XIII - garantia do direito à educação e à aprendizagem ao
longo da vida.

Enquanto marco histórico inserido na evolução dos direitos humanos, a estrutura do direito à educação surgiu na segunda dimensão, os denominados direitos sociais. A Carta

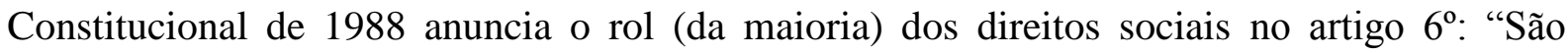
direitos sociais a educação, a saúde, a alimentação, o trabalho, a moradia, o transporte, o lazer, a segurança, a previdência social, a proteção à maternidade e à infância, a assistência aos desamparados, na forma desta Constituição".

E a conceituação fica a par da doutrina, que explica:

[...] os direitos sociais são, à luz do direito positivo-constitucional brasileiro, verdadeiros direitos fundamentais, tanto em sentido formal (pois estão na Constituição e têm status de norma constitucional) quanto em sentido material (pois são valores intimamente ligados ao princípio da dignidade da pessoa humana (MARMELSTEIN, 2009, p. 174).

O direito à educação como direito social, nas palavras de André Ramos Tavares (2016, p. 748), apresenta-se como "um direito matiz social. Ela o faz, inicialmente, [...], de maneira incisiva e sintética, para posteriormente ratificar esse posicionamento, especificando esse direito e outros direitos e institutos correlatos, no seu Capítulo III do Título VIII, exatamente a partir do art. $205 \%$. 
Como típico direito social, o direito à educação obriga o Estado a oferecer o acesso a todos interessados, especialmente àqueles que não possam custear uma educação particular. Os direitos sociais ocupam-se, prioritariamente, dentro do universo de cidadãos do Estado, daqueles mais carentes (TAVARES, 2016, p. 748).

José Afonso da Silva (2009, p. 183-184) clarifica:

[...] "os direitos sociais", como dimensão dos direitos fundamentais do homem, são prestações positivas proporcionadas pelo Estado direta ou indiretamente, enunciadas em normas constitucionais, que possibilitam melhores condições de vida aos mais fracos; direitos que tendem a realizar a igualização de situações sociais desiguais. São, portanto, direitos que se ligam com o direito de igualdade. Valem como pressupostos do gozo dos direitos individuais, na medida em que criem condições materiais mais propícias ao aferimento da igualdade real - o que, por sua vez, proporciona condição mais compatível com o exercício efetivo da liberdade (grifo nosso).

$\mathrm{O}$ ordenamento constitucional pátrio proclama o direito à educação como direito social em seu artigo $6^{\circ}$, na redação dada pela Emenda Constitucional n. 26/2000, de sorte que os direitos sociais caracterizam-se como o conteúdo da ordem social e sua previsão representa um desdobramento da perspectiva da democracia social, impulsionada pelos documentos da Constituição Mexicana (1917), da Constituição de Weimar (1919) e do texto constitucional brasileiro de 1934.

Não obstante, o direito à educação se difere dos outros direitos sociais, pois não se trata de proposta, mas, sim, de premissa, ou seja, o processo educacional deve realizar-se por meio do acesso efetivo, pois elemento condicionante para o próprio exercício dos demais direitos fundamentais, conforme explica Motauri Ciocchetti de Souza (2010, p. 11).

$\mathrm{Na}$ classificação das gerações (ou dimensões) dos direitos fundamentais, os direitos sociais são direitos de segunda dimensão, de modo a indicar as prestações positivas por parte do Estado (perspectiva de democracia social), bem como anunciam como propósito a concretização de uma perspectiva de sociedade igualitária na busca de melhores condições de vida, em sintonia com os fundamentos da República Federativa do Brasil da cidadania e da dignidade humana, nos moldes do artigo $1^{\circ}$ do texto constitucional:

A República Federativa do Brasil, formada pela união indissolúvel dos Estados e Municípios e do Distrito Federal, constitui-se em Estado Democrático de Direito e tem como fundamentos: [...]; II - a cidadania; III - a dignidade da pessoa humana; $[\ldots]$.

Walter Claudius Rothenburg (2014, p. 70) utiliza a terminologia "encarnações” de direitos fundamentais, e não "dimensões" dos direitos fundamentais no sentido de que "o caráter complexo dos direitos fundamentais e as contínuas possibilidades (releituras) que a 
concepção jurídica de cada época lhes oferece permitem aludir metaforicamente às 'encarnações' dos direitos fundamentais, que se renovam a cada 'geração"”.

O processo educacional adequado e com qualidade - ainda que em época de isolamento social - é o instrumento para a formação de cidadãos, ou seja, uma formação democrática, em sintonia com o modelo de Estado brasileiro, o democrático.

Como processo de reconstrução da experiência e atributo da pessoa humana, a educação é autêntico direito da personalidade, motivo porque deve ser acessível a todos e, por todos, significa alcançar a universalidade, mesmo em época de distanciamento social. Assim, se ocorrer dificuldade de acesso à internet, ferramenta indispensável para as aulas em ambiente virtual no período da pandemia, a escola deverá - e a maioria já o faz - auxiliar o material de aula de outra forma, inclusive a dificuldade no acesso das bibliotecas virtuais, a escola encaminha livros físicos pelos correios, sem qualquer custo ao discente.

\title{
2.3 O direito à educação, o Estado Democrático de Direito e a dignidade humana
}

Em relação ao modelo democrático de Direito, destaca-se a explicação de Pietro de Jesús Lora Alarcón (2020, p. 174) que “A democracia é uma qualidade do Estado, configurando-se como princípio fundamental, sobre a base da soberania do povo".

Walter Claudius Rothenburg (2020) expõe a ideia de Fernando de Brito Alves de que “a democracia, para o Direito é uma condição de um Direito legítimo e ela própria é um direito fundamental).

José Afonso da Silva (2005, p. 119-120):

\begin{abstract}
A democracia que o Estado Democrático de Direito realiza há de ser um processo de convivência social numa sociedade livre, justa e solidária (art. $3^{\circ}, \mathrm{I}$ ), em que o poder emana do povo, e deve ser exercido em proveito do povo, diretamente ou por representantes eleitos (art. $1^{\circ}$, parágrafo único); participativa, porque envolve a participação crescente do povo no processo decisório e na formação dos atos de governo, pluralista, porque respeita a pluralidade de ideias, culturas e etnias e pressupõe assim o diálogo entre opiniões e pensamentos divergentes e a possibilidade de convivência de formas de organização e interesses diferentes da sociedade; há de ser um processo de liberação da pessoa humana das formas de opressão que não depende apenas do reconhecimento formal de certos direitos individuais, políticos e sociais, mas especialmente da vigência de condições econômicas suscetíveis de favorecer o seu pleno exercício (grifo nosso).
\end{abstract}

Desta forma, a educação difere de outros direitos sociais e fraternos consagrados na nossa Constituição Federal, pois a educação é premissa - e não proposta, para o efetivo exercício dos demais direitos fundamentais e do papel de cidadão de cada um, de modo a ser 
o único caminho para o alcance do modelo democrático de direito e da dignidade humana.

E a faculdade, com sua autonomia universitária e em busca de atingir seu papel e sua missão de ensino, buscou caminhos alternativos à sala de aula para driblar eventuais prejuízos de conteúdos programáticos e contato dos alunos com os professores, quanto à pesquisa e extensão, encontrou a tecnologia como sua aliada, de modo que a tecnologia - neste momento - é o instrumento democratizador para a efetivação do direito à educação formal do ensino superior.

Para Walter Claudius Rothenburg (2020) defende a importância da potencialização da democracia por meio do uso das ferramentas tecnológicas. Nessa toada, todos os discentes estarão atrelados à democracia e a continuidade dos estudos, por meio do uso da tecnologia, da internet e dos meios de comunicação remota, em respeito ao direito fundamental.

\subsection{A autonomia universitária}

A universidade integra o sistema de ensino superior, cujas diretrizes nacionais, em termos de finalidade, objetivos, etc., devem ser fixadas em lei, nos moldes do inciso XXIV do artigo 22 da Constituição Federal.

Uma significativa inovação da Constituição Brasileira de 5 de outubro de 1988 foi a inserção da autonomia universitária no plano constitucional. Assim, o texto constitucional abriga, ao lado de outras "autonomias", a autonomia universitária, de modo que o constituinte pátrio, certamente, concluiu que o reconhecimento da autonomia universitária pela via legislativa comum (como previsto anteriormente), não foi suficiente para que as universidades realmente pudessem cumprir, de modo autônomo e independente, a sua verdadeira, relevante e indispensável finalidade. A autonomia, que não se confunde com a soberania, consiste na capacidade de autodeterminação e de automação dentro dos limites fixados pelo poder que a institui.

A autonomia universitária está prevista no artigo 207 da Lei Maior, de modo que coube à Constituição de 5 de outubro de 1988 elevar, pela primeira vez na história da universidade no Brasil, a autonomia das universidades ao nível de princípio constitucional: "As universidades gozam de autonomia didático-científica, administrativa e de gestão financeira e patrimonial, e obedecerão ao princípio da indissociabilidade entre ensino, pesquisa e extensão". 
O supracitado artigo dispõe acerca do tripé ensino-pesquisa-extensão, como um imperativo de um ensino com garantia de qualidade e, assim, o respeito ao direito fundamental e social, bem como ao Estado Democrático de Direito, a dignidade humana e o exercício efetivo da cidadania. E, nessa toada, a liberdade de cátedra, apresentada pelos verbos pesquisar e divulgar como elementos da prática docente.

A autonomia universitária é compreendida pela autonomia didático-científica, que espelha a atividade fim; e a autonomia administrativa e de gestão financeira e patrimonial, que corresponde à atividade meio. No que concerne à autonomia-fim (autonomia didática e científica), devem as universidades observar, dentre outros, os princípios do próprio artigo 207 e os contidos no artigo 206, supracitados.

Nessa toada, dispõe o artigo 52 da Lei de Diretrizes e Bases da Educação Nacional que as universidades "são instituições pluridisciplinares de formação dos quadros profissionais de nível superior, de pesquisa, de extensão e de domínio e cultivo do saber humano".

O princípio da autonomia universitária possui uma dimensão fundamentadora, integrativa, diretiva e limitativa própria, pois é no próprio texto da Carta de 1988 que se radica o fundamento do instituto; que se extraí sua força integrativa em todo o sistema federativo do País; que preordena a interpretação que se possa dar ao instituto; que os limites que se podem opor à autonomia universitária têm como sede única a própria Constituição Federal; que o princípio da autonomia universitária, como princípio constitucional, deve ser interpretado em harmonia - mas no mesmo nível - com os demais princípios constitucionais.

Nesse sentido, a lei infraconstitucional - a Lei de Diretrizes e Bases da Educação Nacional - prevê, em seu artigo 43, as finalidades da educação superior, in verbis:

I - estimular a criação cultural e o desenvolvimento do espírito científico e do pensamento reflexivo; II - formar diplomados nas diferentes áreas de conhecimento, aptos para a inserção em setores profissionais e para a participação no desenvolvimento da sociedade brasileira, e colaborar na sua formação contínua; III incentivar o trabalho de pesquisa e investigação científica, visando o desenvolvimento da ciência e da tecnologia e da criação e difusão da cultura, e, desse modo, desenvolver o entendimento do homem e do meio em que vive; IV promover a divulgação de conhecimentos culturais, científicos e técnicos que constituem patrimônio da humanidade e comunicar o saber através do ensino, de publicações ou de outras formas de comunicação; V - suscitar o desejo permanente de aperfeiçoamento cultural e profissional e possibilitar a correspondente concretização, integrando os conhecimentos que vão sendo adquiridos numa estrutura intelectual sistematizadora do conhecimento de cada geração; VI estimular o conhecimento dos problemas do mundo presente, em particular os nacionais e regionais, prestar serviços especializados à comunidade e estabelecer com esta uma relação de reciprocidade; VII - promover a extensão, aberta à participação da população, visando à difusão das conquistas e benefícios resultantes 
da criação cultural e da pesquisa científica e tecnológica geradas na instituição; VIII - atuar em favor da universalização e do aprimoramento da educação básica, mediante a formação e a capacitação de profissionais, a realização de pesquisas pedagógicas e o desenvolvimento de atividades de extensão que aproximem os dois níveis escolares.

Na sequência, o artigo 44 reza acerca dos cursos e programas:

I - cursos sequenciais por campo de saber, de diferentes níveis de abrangência, abertos a candidatos que atendam aos requisitos estabelecidos pelas instituições de ensino, desde que tenham concluído o ensino médio ou equivalente;

II - de graduação, abertos a candidatos que tenham concluído o ensino médio ou equivalente e tenham sido classificados em processo seletivo;

III - de pós-graduação, compreendendo programas de mestrado e doutorado, cursos de especialização, aperfeiçoamento e outros, abertos a candidatos diplomados em cursos de graduação e que atendam às exigências das instituições de ensino;

IV - de extensão, abertos a candidatos que atendam aos requisitos estabelecidos em cada caso pelas instituições de ensino.

Preconiza o artigo 53 da Lei as atribuições das universidades, dentre outras:

No exercício de sua autonomia, são asseguradas às universidades, sem prejuízo de outras, as seguintes atribuições:

I - criar, organizar e extinguir, em sua sede, cursos e programas de educação superior previstos nesta Lei, obedecendo às normas gerais da União e, quando for o caso, do respectivo sistema de ensino; II - fixar os currículos dos seus cursos e programas, observadas as diretrizes gerais pertinentes; III - estabelecer planos, programas e projetos de pesquisa científica, produção artística e atividades de extensão; [...].

O inciso V do artigo 208 da Carta de 1988 prevê a democratização do ensino superior, nos seguintes moldes "V - acesso aos níveis mais elevados do ensino, da pesquisa e da criação artística, segundo a capacidade de cada um", de sorte que se tem a previsão e proteção da acessibilidade do ensino superior, bem como da qualidade deste ensinoaprendizagem, mesmo em tempos de isolamento social.

O direito à educação - formal, ofertada pelo ensino-aprendizagem, é uma prática educativa que leva o aluno a "aprender, a saber, pensar, criar, inovar, construir conhecimentos, participar ativamente de seu próprio conhecimento" (LANDIM, 1997, p. 10).

Nessa esteira, a universidade apresenta continuidade no seu papel e sua missão ao ofertar o ensino, ainda que em ambiente virtual, de modo a dar sequencia ao tripé da educação, o ensino-aprendizagem, a extensão e a pesquisa.

A eficácia do direito à educação por meio da prestação de serviço do ensino está na complementariedade do ensino presencial e a utilização da tecnologia e os meios de comunicação remota, ou seja, a interatividade, o interesse e o esforço (da instituição, dos 
professores e alunos) e, desse modo, o alcance da excelência do ensino com qualidade nas instituições educativas que se valeram do ambiente virtual nessa época da pandemia do novo coronavírus.

\section{A TECNOLOGIA COMO INSTRUMENTO DEMOCRATIZADOR PARA EFETIVAÇÃO DO DIREITO À EDUCAÇÃO NOS TEMPOS DE PANDEMIA DE COVID-19}

A situação atual do Brasil - e de todo o mundo, é de isolamento social e proibição de aglomeração, como medidas para diminuir o avanço do contágio no novo coronavírus e, assim, alcançar o distanciamento social exigido. Como consequência, alterações nas rotinas das escolas, vez que a aula não pode ser lecionada nos moldes tradicionais, com muitas pessoas no mesmo espaço físico.

A crise da pandemia do COVID-19 não pode ocasionar em exclusão dos estudantes, de modo que as instituições, aqui, em especial, as de ensino superior, deverão (e estão) adequando-se para alcançar todos os seus alunos.

A Carta Cidadã elevou o direito à educação como direito social ao prever, em seu artigo 60: "São direitos sociais a educação, a saúde, a alimentação, o trabalho, a moradia, o transporte, o lazer, a segurança, a previdência social, a proteção à maternidade e à infância, a assistência aos desamparados, na forma desta Constituição".

O direito social à educação possui como característica a universalidade, de modo que se trata de direito de todos e, nessa esteira, deve ser ofertado a todos. A universalidade do direito à educação para todas as pessoas, em período de necessário distanciamento e isolamento social, a oferta do ensino por meio da tecnologia e com a utilização dos meios de comunicação, as instituições buscam alcançar a totalidade dos seus alunos, mesmo aqueles que não possuem o acesso à rede mundial de computadores - a internet, de modo que a preocupação de professores, coordenadores de cursos e gestores de instituições têm tomado providencias para esta efetivação, como, por exemplo, a possibilidade de o discente utilizar-se de computador com internet da própria escola, em ambiente isolado, de acordo com as orientações das autoridades públicas.

Também, o acesso a bibliotecas virtuais e, aquele aluno que não consiga este acesso, receberá, em sua casa, - e sem qualquer custo- a obra física enviada pela instituição. 
Os professores e as instituições têm se adequado - e, aqui, ênfase na expressão "adequação", vez que, em curto período de tempo, os docentes se (re)inventaram de acordo com a necessidade do isolamento social e a não possibilidade de aulas nos moldes regulares, de modo a passarem a lecionar em salas virtuais, ao vivo e com interação dos alunos, valendose dos meios de comunicação remota, de modo que a tecnologia passou a exercer o papel de instrumento democratizador do direito à educação.

É de suma importância o destaque à preocupação dos professores quanto ao desenvolvimento das competências, quais sejam: os conhecimentos e as habilidades relacionadas àquele conteúdo - e não somente ao conteúdo e carga horária.

Os professores e instituições de ensino superior viram a necessidade - em um curtíssimo espaço de tempo - de entender e aprender o domínio das ferramentas de transmissão e, assim, uma nova forma de organização educativa e da utilização da tecnologia com o novo formato do ambiente virtual para o ensino-aprendizagem pesquisa e extensão, de modo que a sala em ambiente virtual substituiu, tendo em vista a exigência do período enfrentado pela sociedade,

As orientações das autoridades públicas para o isolamento social durante a pandemia do novo coronavírus levaram à realidade de descontinuidade dos encontros presenciais, inclusive nas instituições de ensino.

Com a suspensão das aulas presenciais e para que esta situação não acarreasse em prejuízo no andamento dos estudos, a solução encontrada pelas instituições de ensino superior foi a opção apresentada pela Portaria n. 343 do Ministério da Educação e Cultura, de 17 de março de 2020, para a utilização da tecnologia e os meios de comunicação remota para a continuidade das rotinas acadêmicas.

A Portaria n. 343 do Ministério da Educação e Cultura autorizou a substituição das aulas presenciais por aulas realizadas com o uso da tecnologia e dos meios de comunicação remota, conforme norma do seu artigo $1^{\circ}$.

O parágrafo $2^{\circ}$ do artigo $1^{\circ}$ dispôs acerca da responsabilidade das instituições a definição das matérias que teriam a substituição aplicada, bem como a responsabilidade quanto à disponibilização das ferramentas aos alunos para o acompanhamento dos conteúdos, aulas e avaliações, durante o período da pandemia do coronavírus e a necessidade de adotar medidas para diminuir o avanço do contágio do vírus.

Art. $1^{\circ}$ Autorizar, em caráter excepcional, a substituição das disciplinas presenciais, em andamento, por aulas que utilizem meios e tecnologias de informação e 
comunicação, nos limites estabelecidos pela legislação em vigor, por instituição de educação superior integrante do sistema federal de ensino, de que trata o art. $2^{\circ}$ do Decreto $n^{\circ} 9.235$, de 15 de dezembro de 2017.

[...]

$\S 2^{\circ}$ Será de responsabilidade das instituições a definição das disciplinas que poderão ser substituídas, a disponibilização de ferramentas aos alunos que permitam o acompanhamento dos conteúdos ofertados bem como a realização de avaliações durante o período da autorização de que trata o caput.

Walter Claudius Rothenburg (2020) explana que "a internet é indispensável para eficiência da democracia".

E a tecnologia e o surgimento da internet, como um espaço físico, que possibilita que:

pessoas se comuniquem, façam negócios e compartilhem ideias. Assim, trata-se de uma importante ferramenta para integrar economias locais na economia global, estabelecer trocas de conhecimento e culturas, ou seja, é um novo espaço para que pessoas, profissionais, empresas e até mesmo Estados estabeleçam sua presença no mundo (SARTORI, 2015, p. 98).

Gustavo Testa Corrêa (2002, p. 4) preocupou-se com a relação da pessoa e as novas tecnologias, de modo a buscar, pelos operadores do direito, a convivência entre as duas figuras.

Antonio-Enrique Pérez Luño (2014, p. 10) dispõe sobre as características da "sociedade da informação" ou a "era da internet":

\begin{abstract}
El contexto en el que se ejercitan hoy los valores democráticos y los derechos humanos es el de una sociedad donde las Nuevas Tecnologías (NT) y las Tecnologías de la Información y de la Comunicación (TIC) y, en especial, la Red han devenido el símbolo emblemático de nuestra cultura. En el momento presente, para designar el marco de nuestra convivencia se alude reiteradamente a expresiones tales como la "sociedad de la información", la "sociedad informatizada" o la "era de Internet". Para las nuevas generaciones (indignadas o no), "ya está todo en la Red". Y lo que no está, no merece la pena conocerse. Las TIC y la NT, han producido nuevas formas

Los vivir de formas nuevas producido han NT, la y TIC Los valores democráticos, pero, como contrapunto, han engendrado también nuevos riesgos para el ejercicio y la tutela de las libertades. Las posibilidades de intromisión en la intimidad y de colonización de la vida privada a través de medios tecnológicos, han suscitado constante inquietud cívica en las sociedades avanzadas. Es sabido que la etapa actual de desarrollo tecnológico, ha generado nuevos fenómenos de agresión a los derechos y libertades (grifo nosso).
\end{abstract}

Apesar de o autor expor o uso da tecnologia na participação do cidadão na vida política, extrai-se de seu texto que a era tecnológica constitui um novo horizonte dos valores democráticos e dos direitos de liberdade, conforme trecho abaixo destacado. E, nesse sentido, faz-se o vínculo com a liberdade que impera no direito à educação, em especial, o da 
autonomia da universidade, tratado em tópico posterior.

Las NT y las TIC permiten, en efecto, un reforzamiento de los valores cívicos y nuevas formas de ejercicio de los derechos y pueden contribuir a un reforzamiento del tejido participativo de las sociedades democráticas. La ciberciudadanía y la teledemocracia constituyen un nuevo horizonte de los valores y de derechos (LUÑO, 2014, p. 11).

Continua o autor,

Cada época confiere a las instituciones jurídicas y políticas que en ella operan un perfil característico. El signo de nuestro tiempo se distingue por la omnipresencia de las NT y las TIC en todos los aspectos de la vida individual y colectiva. En los últimos años se ha ampliado decisivamente la incidencia de las TIC y las NT en amplios sectores de la experiencia jurídica y política. Ello invita a plantear también su repercusión en el alcance y ejercicio de los derechos humanos derechos (LUÑO, 2014, p. 11).

Hoje, mais do que nunca se precisou, a pessoa necessita da internet para dar sequência à sua rotina - de trabalho e de estudo - no período de isolamento social em razão da pandemia do COVID-19 que o mundo atravessa; e, em especial, no estudo em tela, a transformação que essa realidade causou no ensino.

\footnotetext{
Com o intuito de amenizar os prejuízos causados pela pandemia do novo coronavírus, o Ministério da Educação (MEC) autorizou as instituições de ensino superior públicas e privadas de todo o Brasil a substituírem as disciplinas presenciais por aulas à distância, a educação on-line é imprescindível neste momento (REPUBLICANOS10, 2020).
}

As faculdades optaram pela suspensão das aulas presenciais e, assim, a substituição por aulas em salas virtuais, e, para isso, contou com a tecnologia e meios de comunicação, para dar continuidade aos conteúdos programáticos, com aulas virtuais - por meio de plataformas digitais - nos mesmos dias e horários antes reservados às atividades presenciais, de modo a não causar prejuízo aos alunos, no período de isolamento social, em sintonia com a Portaria n. 323 do Ministério da Educação e Cultura, datado de 17 de março 2020.

A solução encontrada pelas universidades está fundamentada no princípio da garantia do padrão de qualidade do ensino, previsto no inciso IX do artigo $3^{\circ}$ da Lei de Diretrizes e Bases da Educação Nacional e em busca da sua finalidade, o ensino-aprendizagem, pesquisa e extensão.

Nesse sentido, a possibilidade do acesso à aula em ambiente virtual, por meio de plataformas digitais ofertadas pelas instituições aos seus docentes e discentes (ou seja, o envolvimento dos atores), permite que todos os alunos assistam às aulas, em locais diversos, cada um na sua casa, com o cuidado aos parentes que dele necessitam (como filhos e idosos), 
como respeito e obediência às orientações das autoridades públicas como mediadas de contenção da proliferação do novo coronavírus e, também, levando-se em conta os princípios da solidariedade e da humanidade, que devem reger todas as relações entre pessoas nesse período tão delicado que a sociedade atravessa.

Dessa forma, o uso da tecnologia nas rotinas acadêmicas permite o alcance do modelo democrático de Estado, o modelo brasileiro e a efetivação do direito à educação e a proteção à dignidade humana.

\section{CONSIDERAÇÕES FINAIS}

O processo educacional está intimamente ligado ao Estado Democrático de Direito e a dignidade humana.

Em virtude do isolamento social e as orientações das autoridades públicas para a contenção da proliferação do vírus COVID-19, a solução encontrada pelas universidades de ensino superior foi a modalidade de aulas em salas virtuais, como mecanismo para a continuidade do papel e missão das instituições, em relação ao tripé da educação formal, ou seja, o ensino-aprendizagem, a pesquisa e a extensão.

Essa nova forma de aula possibilitou o acesso dos discentes, bem como agilizou a instrução e permitiu a interação entre professores e alunos durante esse período tão delicado e crítico que a sociedade atual enfrenta.

Dessa forma, deu-se continuidade aos estudos e conteúdos programáticos de cada disciplina, bem, como a realização de atividades com problemas práticos a serem solucionados e a realização de avaliações, de modo a respeitar a proposta didática para a construção do conhecimento. Além da racionalidade, há a preocupação com o campo dos afetos, de sorte que mantém, ainda que virtualmente, o relacionamento entre professor e aluno, em que figuram a lealdade, o comprometimento e a confiança.

As instituições de ensino superior decidiram como solução que as aulas fossem totalmente transferidas para o ambiente virtual, a dar continuidade às rotinas acadêmicas, de ensino-aprendizagem, pesquisa e extensão. Esta resposta surgiu do produto da sociedade em período de isolamento social e a tecnologia apresentou-se como instrumento democratizador de efetivação do direito à educação no enfretamento à barreira do distanciamento social exigido e, assim, o respeito ao modelo democrático de Estado brasileiro, à dignidade humana, 
e ao desenvolvimento do papel de cidadão.

\section{REFERÊNCIAS BIBLIOGRÁFICAS}

ALARCÓn, Pietro de Jesús Lora. Ciência Política, Estado e Direito Público: uma introdução ao Direito Público da contemporaneidade. 4. ed. São Paulo: Tirant lo Blanch, 2020.

ARAUJO, Luiz Alberto David; NUNES JÚNIOR, Vidal Serrano. Curso de Direito Constitucional. 22. ed. São Paulo: Verbatim, 2018.

BRASIL. Constituição Federal de 1988. Disponível em:

http://www.planalto.gov.br/ccivil 03/constituicao/constituicaocompilado.htm. Acesso em: 10 . abr. 2020.

. Lei de Diretrizes e Bases da Educação Nacional (Lei n. 9.394/1996). Disponível em: http://www.planalto.gov.br/ccivil_03/LEIS/19394.htm. Acesso em: 10. abr. 2020.

Portaria n. 343. Ministério da Educação e Cultura. Disponível em:

http://www.planalto.gov.br/CCIVIL_03/Portaria/PRT/Portaria\%20n\%C2\%BA\%20343-20mec.htm. Acesso em: 10 abr. 2020.

CAPUCHO, Vera Alves Crispim. Educação em tempos de pandemia da COVID-19.

Justificando. 7 abr. 2020. Disponível em:

https://www.justificando.com/2020/04/07/educacao-em-tempos-de-pandemia-da-covid-19/. Acesso em: 10 abr. 2020.

CHALITA, Gabriel Benedito Isaac. Educação - a solução está no afeto. 5. ed. São Paulo: Gente, 2001.

CORRÊA, Gustavo Testa. Aspectos Jurídicos da Internet. 2 ed. São Paulo: Saraiva, 2002. DURKHEIM. Émile. Educação e sociologia. São Paulo: Melhoramentos, 1978.

FGV. Especialistas debatem transformação da educação em meio à pandemia de COVID-19. Portal FGV. 02 abr. 2020. Disponível em: https://portal.fgv.br/noticias/especialistasdebatem-transformacao-educacao-meio-pandemia-covid-19. Acesso em: 10 abr. 2020.

FREIRE, Paulo. Pedagogia da autonomia: saberes necessários à prática educativa. São Paulo: Paz e Terra, 1996. (coleção Leitura)

LEONARDI, Marcel. Tutela e privacidade na internet. São Paulo: Saraiva, 2011.

HERMIDA, Jorge Fernando; BONFIM, Cláudia Ramos de Souza. A educação à distância: história, concepções e perspectivas. Revista HISTEDBR on-line. Campinas. n. especial. ago. 2066, p. 166-181.

LANDIM, Cláudia Maria das Mercês Paes Ferreira. Educação à distância: algumas considerações. Rio de Janeiro, 1997. 
LITTO, Fredric Michael. A solução para o distanciamento social está à mão: EAD. Revista Educação. 28 mar. 2020. Disponível em: https://revistaeducacao.com.br/2020/03/28/eadabed/. Acesso em: 22. abr. 2020.

LUÑO, Antonio-Enrique Pérez. Teledemocracia, ciberciudadania y derechos humanos. Teledemocracia, ciberciudadania y derechos humanos. Revista Brasileira de Políticas Públicas (Brazilian Journal of Publicy Policy). UniCEUB. ISSN 2236-1677. v. 4. n. 2. Juldez 2014. p. 9-45.

MARMELSTEIN, George. Curso de Direitos Fundamentais. 2. ed. São Paulo: Atlas, 2009.

ROTHENBURG, Walter Claudius. Democracia e suas versões contemporâneas. Bauru. Centro Universitário de Bauru mantido pela Instituição Toledo de Ensino, 2020. Disponível em: https://zoom.us/my/ite.eventos. Acesso em: 30 abr. 2020.

Direitos fundamentais. São Paulo: Método, 2014.

REPUBLICANOS 10. Educação on-line em tempo de distanciamento social. 01 abr. 2020. Disponível em: https://republicanos10.org.br/noticias/republicanos-nacional/educacao-onlineem-tempo-de-distanciamento-social/. Acesso em: 22. abr. 2020.

SARLET, Ingo Wolfgang. Dignidade da Pessoa Humana e Direitos Fundamentais na Constituição Federal de 1988. 2. ed. Porto Alegre: Livraria do Advogado, 2002.

SAVATER, Fernando. A educação como a ferramenta para se criar cidadãos. Fronteiras do Pensamento. 2015. Disponível em: https://www.fronteiras.com/conferencistas/fernandosavater. Acesso em: 20 abr. 2020.

SARTORI, Ellen Carina Mattias. O Direito Fundamental à Privacidade e a Proteção de Dados Pessoais: uma análise em face da sociedade de consumo na era da internet. Dissertação (Mestrado). 228 f. Instituição Toledo de Ensino, Centro de Pós-Graduação, Orient. Prof. Dr. Fábio Alexandre Coelho. Bauru, 2015.

SEVERINO, Antônio Joaquim. Metodologia do Trabalho Científico. 24. ed. São Paulo: Cortez, 2016.

SILVA, José Afonso da. Curso de Direito Constitucional Positivo. 24. ed. São Paulo: Malheiros, 2005.

SOUZA, Moutauri Ciocchetti de. Direito da Educação. In: NUNES JUNIOR, Vidal Serrano (coord.). Manual de Direitos Difusos. 2. ed. São Paulo: Verbatim, 2012. Direito Educacional. São Paulo: Verbatim, 2010.

TAVARES, André Ramos. Curso de Direito Constitucional. 14. ed. São Paulo: Saraiva, 2016.

TOLEDO, Cláudia Mansani Queda de. Direito à liberdade de cátedra. Enciclopédia jurídica 
da PUC-SP. 2017. Celso Fernandes Campilongo, Alvaro de Azevedo Gonzaga e André Luiz Freire (coords.). Tomo: Direito Administrativo e Constitucional. Vidal Serrano Nunes Jr., Maurício Zockun, Carolina Zancaner Zockun, André Luiz Freire (coord. de tomo). São Paulo: Pontifícia Universidade Católica de São Paulo, 2017. Disponível em:

https://enciclopediajuridica.pucsp.br/pdfs/direito-a-liberdade-de-catedra_58edb3c1e83a0.pdf. Acesso em: 10 abr. 2020.

Educação: uma nova perspectiva para o Estado Democrático de Direito Brasileiro. São Paulo: Verbatim, 2015.

O Ensino Jurídico no Brasil e o Estado Democrático de Direito: análise crítica ao ensino do Direito Penal. São Paulo: Verbatim, 2015.

VERGARA, Sylvia Constant. Estreitando relacionamentos na educação à distância.

Cadernos EBAPE.BR. Rio de Janeiro. v. 5. 2007. 